\title{
Limited Maternal Fuel Availability due to Hyperinsulinemia Retards Fetal Growth and Development in the Rat
}

\author{
EDWARD S. OGATA, RONALD I. PAUL, AND SANDRA L. FINLEY \\ Departments of Pediatrics, Obstetrics and Gynecology, Northwestern University Medical School, Northwestern \\ Memorial Hospital, and Children's Memorial Hospital, Chicago, Illinois
}

\begin{abstract}
We rendered pregnant rats chronically hyperinsulinemic to determine the effect of reduced maternal metabolic fuel availability on fetal growth and development. We implanted osmotically driven insulin loaded minipumps on day 14 (term 21.5 days) in pregnant rats. This significantly increased maternal plasma concentrations of insulin and reduced glucose from day 15 until term. From day 17 until birth, fetal growth was significantly less for hyperinsulinemic mothers (term birth weight $4.53 \pm 0.07$ versus $5.64 \pm 0.06 \mathrm{~g}, p<0.001$ ). In fetuses of hyperinsulinemic mothers plasma glucose and insulin concentrations were significantly reduced while glucagon concentrations were increased. Total plasma amino acids were significantly reduced in maternal rats and their fetuses from days 17 to 19 while arteriovenous blood gas tensions and pH did not differ between fetuses of hyperinsulinemic and control mothers. Small for gestational age newborn pups of hyperinsulinemic mothers were hypoglycemic for the first $\mathbf{2 4 0}$ min of life as a result of limited hepatic glycogen stores and a delay in the normally expected induction of hepatic cytosolic phosphoenolpyruvate carboxykinase. This occurred despite significant increases in neonatal plasma glucagon concentrations. These data indicate that limitation of maternal glucose and amino acids with normal placental gaseous exchange retards fetal growth, limits hepatic glycogen deposition, and delays neonatal phosphoenolpyruvate carboxykinase induction. Limited fetal insulin secretion resulting from diminished maternal fuel availability may have also been a factor in retarding growth. The delay in phosphoenolpyruvate carboxykinase induction despite enhanced glucagon secretion during fetal and neonatal life suggests a specific "resistance" to this hormone in the rat growth retarded by limited metabolic fuel availability. (Pediatr Res 22: 432-437, 1987)
\end{abstract}

\section{Abbreviations}

PEPCK, phosphoenolpyruvate carboxykinase

BOHB, betahydroxybutyrate

$\mathrm{SGA}_{\mathbf{l}}$, small for gestational age related to maternal hyperinsulinemia

Intrauterine growth retardation is often ascribed to "uteroplacental insufficiency," (1) a poorly defined condition. In previous studies, we mimicked "uteroplacental insufficiency" in the rat

Received March 18, 1987; accepted May 12, 1987.

Correspondence Edward S. Ogata, M.D., Division of Neonatology, Prentice Women's Hospital, 333 East Superior Street, Room 1106, Chicago, IL 60611.

Supported in part by NIH Grants I PO 119070 and RR 05370. by maternal uterine artery ligation, a well-established method for retarding fetal growth $(2,3)$. This reduces fetal arteriovenous oxygen tension and $\mathrm{pH}$, increases carbon dioxide tension, and reduces glucose and branched-chain amino acid concentrations in the fetus (4). The relative importance of each alteration in limiting fetal growth is unknown.

A method (5) by which the maternal rat is rendered chronically hyperinsulinemic during late gestation offered a potential means to determine the extent to which limiting metabolic fuels without altering blood gas tensions or $\mathrm{pH}$ affects fetal growth and development. Using this, we found that maternal hyperinsulinemia decreases concentrations of glucose and amino acids in the mother and fetus. This limits fetal growth although not to the same degree as with maternal uterine artery ligation in which both fuel availability and gaseous exchange are impaired. This restriction of maternally derived metabolic fuels also affects fetal biochemical development since growth retarded newborn pups of hyperinsulinemic mothers become hypoglycemic as a result of limited glycogen stores and delayed induction of hepatic PEPCK.

\section{MATERIALS AND METHODS}

We adapted the method of Grupposo et al. (5) to cause maternal hyperinsulinemia. On day 14 (term 21.5 days) of gestation, we anesthetized 9-wk-old pregnant rats with ketamine $(30$ $\mathrm{mg} / \mathrm{kg}$ body weight) and implanted a $2.2 \times 0.5 \mathrm{~cm}$ osmotically driven minipump in the subcutaneous tissue of the dorsum of the neck after local administration of $1 \%$ xylocaine. Animals awakened within $1 \mathrm{~h}$. The minipump (Alzet Corp., Palo Alto, CA) had been filled with porcine insulin in glycerol (Iletin II, U500 , Eli Lilly, Indianapolis, IN) and placed in $154 \mathrm{mM} \mathrm{NaCl} 24$ $\mathrm{h}$ before implantation to prepare its cellulose ester membrane. Once implanted, the minipumps continuously deliver $0.42 \mathrm{U}$ of insulin/h for the duration of gestation. Control rats received minipumps loaded with $154 \mathrm{mM} \mathrm{NaCl}$. Rats had ad libitum access to standard rat chow (Purina, St. Louis, MO). Rats with insulin pumps were supplied with a glucose solution $(10 \% \mathrm{v} / \mathrm{v})$ rather than water. We measured maternal weight and food intake daily and obtained blood from the cut tail tip of awake mothers.

We performed two series of studies to characterize the effect of maternal hyperinsulinemia in the offspring. In the first series, we sequentially measured growth and metabolic variables of fetuses from days 18 through 21 of gestation, and in the second series we measured metabolic fuels and hormones related to glucoregulation in newborn pups during the first $240 \mathrm{~min}$ of life. We used only fetuses and pups from mothers with eight or more in a litter to control for the effect of litter size on fetal growth.

Fetal studies. To estimate maternal-fetal fuel provision and gaseous exchange, we adapted the method of Girard et al. (6) in which blood is sampled from the fetus with the fetal-placental 
circulation intact. The mother was anesthetized and the uterus exposed and sequentially incised so that individual fetuses could be removed leaving the placenta attached to the uterine wall. We sampled only two to three fetuses from a litter in order to avoid any potential effect of prolonged maternal anesthesia. Thus eight to 12 litters are represented in each group. The fetuses were dried and maintained at $37^{\circ} \mathrm{C}$ with heat lamp and warm moist gauze, and care was taken not to apply tension to the umbilical cord. Fetal blood was obtained from cut axillary vessels and maternal blood obtained simultaneously from the cut tail tip. After blood sampling the fetus was killed by decapitation and the liver quickly removed and frozen in liquid nitrogen. In selected litters, we measured mixed arteriovenous gas tensions and $\mathrm{pH}$ as previously reported (4). We measured carcass and placental weight, plasma concentrations of glucose, insulin, and glucagon, hepatic cytosolic PEPCK activity, and glycogen concentrations. We could measure only fetal body weight and plasma glucose concentrations on days 14 to 16 .

Newborn studies. We have reported our technique for determination of metabolic variables in the newborn (3). On day 21.5, rat pups were delivered by cesarean section after stunning and cervical dislocation of the mother. Pups were quickly dried, separated from their placentas, and placed in chambers which provide humidified room air at $37^{\circ} \mathrm{C}$. Pups had blood collected from the severed axillary artery and were then decapitated. The liver was quickly frozen. We measured sequentially the changes in glucose, insulin, glucagon, and hepatic glycogen concentrations in littermates of hyperinsulinemic and control mothers at $0,20,60,120$, and $240 \mathrm{~min}$ and hepatic cytosolic PEPCK activity at 0,120 , and $240 \mathrm{~min}$.

Analyses. Plasma glucose concentrations (Beckman II Glucose Analyzer) were determined for each fetus and pup. Blood for hormone analysis was treated with Aprotinin (Trasylol 25:1 V/ V) and the plasma frozen at $-20^{\circ} \mathrm{C}$ until assay. The limited amount of plasma obtained from each fetus or pup sometimes precluded measurement of both insulin and glucagon in each sample. Similarly, both glycogen and PEPCK could not be measured for each fetus or pup because of limited liver mass. A separate series of fetuses and their mothers had plasma amino acid concentrations determined.

Our analytical techniques have been reported (2-4). Both plasma insulin and glucagon concentrations were determined with double antibody radioimmunoassay with rat insulin and porcine glucagon respectively as standards. Hepatic cytosolic PEPCK activity and glycogen concentrations were determined as before. Mixed arteriovenous blood gas tensions and $\mathrm{pH}$ were determined with an ILC 1301 automated blood gas analyzer. Plasma BOHB and amino acids were determined as before.

Statistical analysis was performed using the Student's paired $t$ test for comparison of values within a series and unpaired $t$ test for comparison of values between groups (7). Analysis was performed on a Cyber 170-780 computer at the Vogelback Computer Center of Northwestern University. Data are presented as the mean \pm SEM. Values from at least 25 fetuses or pups are represented in each measurement.

\section{RESULTS}

Maternal. Maternal rats with insulin loaded pumps had significantly diminished plasma glucose and elevated insulin concentrations compared to controls from day 15 until term (Fig. 1). Plasma BOHB did not differ between hyperinsulinemic and control mothers and ranged from 0.050 to $0.069 \mu \mathrm{mol} / \mathrm{ml}$ on each day of gestation.

While maternal weight gain expressed as body weight or percent increase from baseline did not differ between hyperinsulinemic and control rats, as gestation progressed the weight of the mother excluding uterine contents was significantly greater in hyperinsulinemic than control mothers as a result of the retarded fetal growth of hyperinsulinemic mothers. We compared the
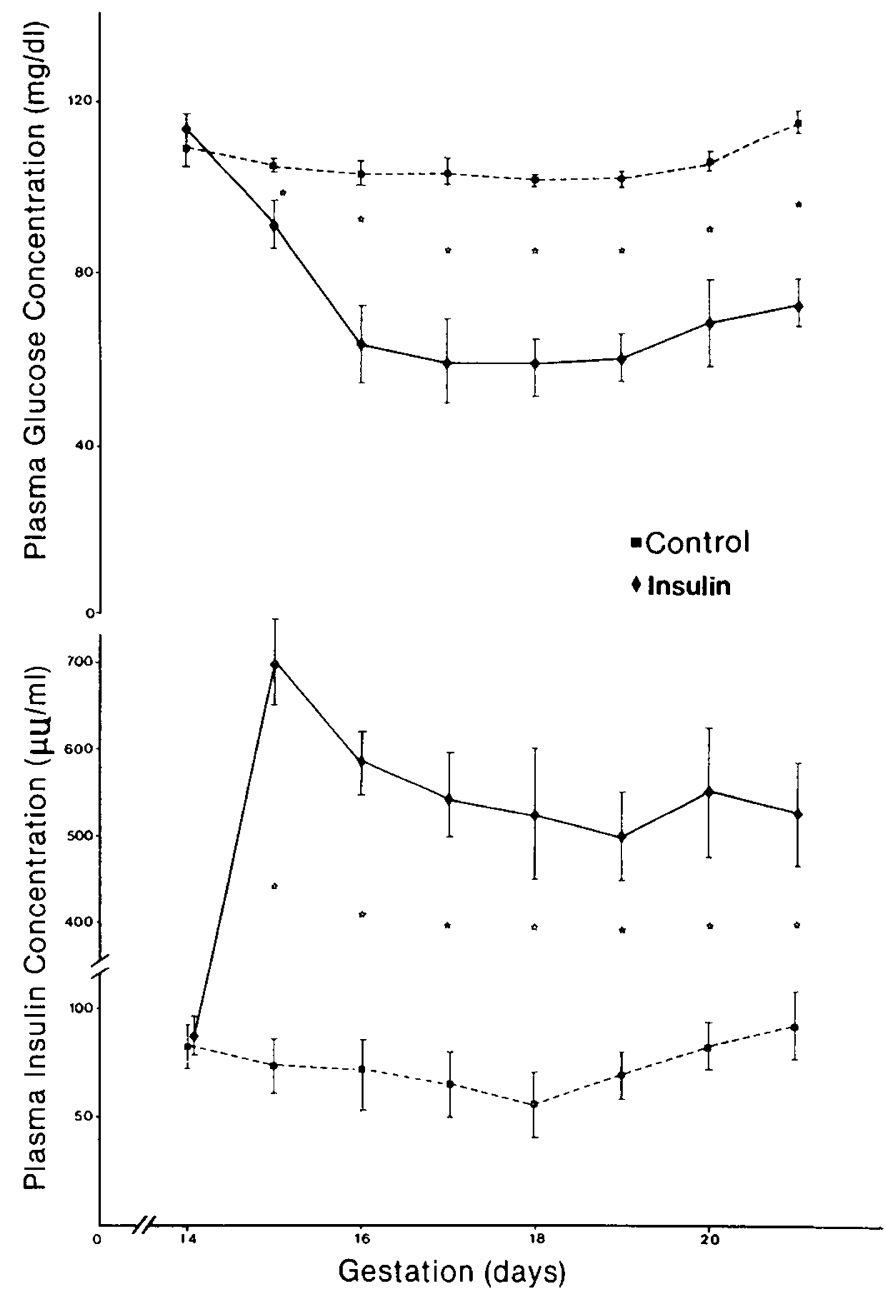

Fig. 1. Maternal plasma glucose and insulin concentrations. By $24 \mathrm{~h}$ following implantation, mothers with insulin-loaded pumps have significantly diminished plasma glucose and elevated insulin concentrations $\left({ }^{*} p<0.01\right.$ to 0.001$)$.

weight of the total conceptus relative to that of the mother by the relation: mass of all fetuses and placentas/total maternal weight (8). The total conceptus on day 17 comprised approximately 0.025 of total maternal weight in controls and 0.020 in mothers receiving insulin. By day 21 , this was 0.19 of total body weight in controls and 0.16 in mothers receiving insulin. The values in controls reflect the rapid growth of the conceptus relative to maternal weight during late gestation. These values were significantly less for hyperinsulinemic mothers from day 17 onward $(p<0.01$ to 0.001$)$.

Fetal. From days 14 to 16 , fetal body and placental weight did not differ between hyperinsulinemic and control mothers, while from day 17 onward, fetuses and placentas of hyperinsulinemic mothers were significantly lighter. We therefore termed the fetuses of hyperinsulinemic mothers as $\mathrm{SGA}_{\mathrm{I}}$ (Fig. 2). On days 15 through $21, \mathrm{SGA}_{1}$ fetuses had significantly lower plasma glucose concentrations than controls. This probably resulted from diminished maternal glucose concentrations since fetal/maternal glucose ratios were equivalent between $\mathrm{SGA}_{\mathrm{I}}$ and control mothers on all days (Table 1). Hepatic concentrations of glycogen were significantly lower in fetuses of hyperinsulinemic mothers from days 17 to 21 . From days 19 to 21 , hepatic glycogen concentrations in $\mathrm{SGA}_{\mathrm{I}}$ fetuses were $10.0 \pm 0.3,18.1 \pm 3.2$, and $34.1 \pm$ $5.0 \mathrm{mg} / \mathrm{g}$ liver and in control fetuses, $29.0 \pm 6.3,38.9 \pm 5.8$, and $49.0 \pm 4.6 \mathrm{mg} / \mathrm{g}$ liver ( $p<01$ to .001 for all values).

On days 17,18 , and 19 , total amino acids were significantly 


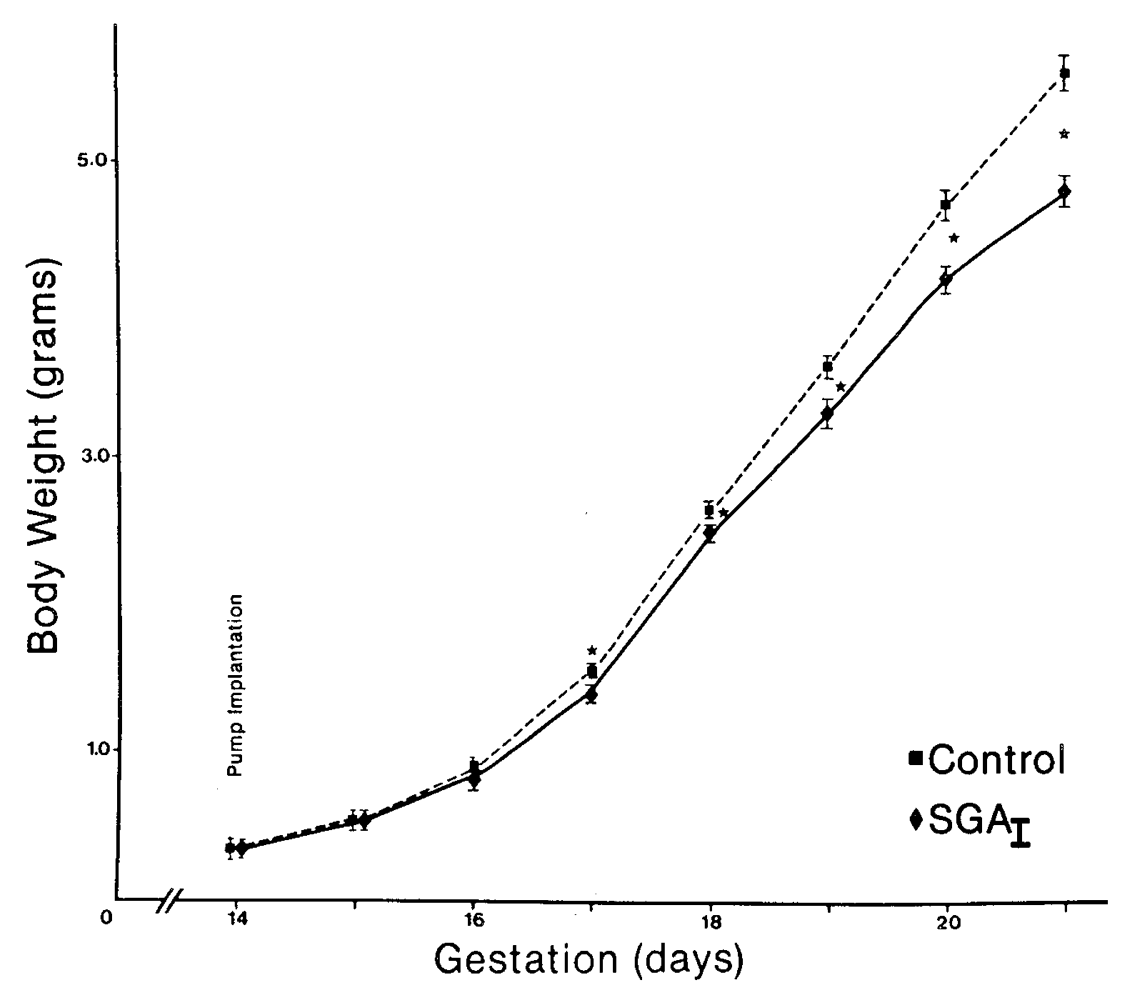

Fig. 2. Intrauterine growth of pups hyperinsulinemic $\left(\mathrm{SGA}_{\mathrm{I}}\right)$ and control mothers. From day 17 onward, $S G \mathrm{~A}_{\mathrm{I}}$ fetuses weighed significantly less than controls $\left({ }^{*} p<0.01\right.$ to 0.001$)$.

Table 1. Fetal plasma glucose ( $\mathrm{mg} / \mathrm{dl}$ ) and fetal/maternal glucose ratios

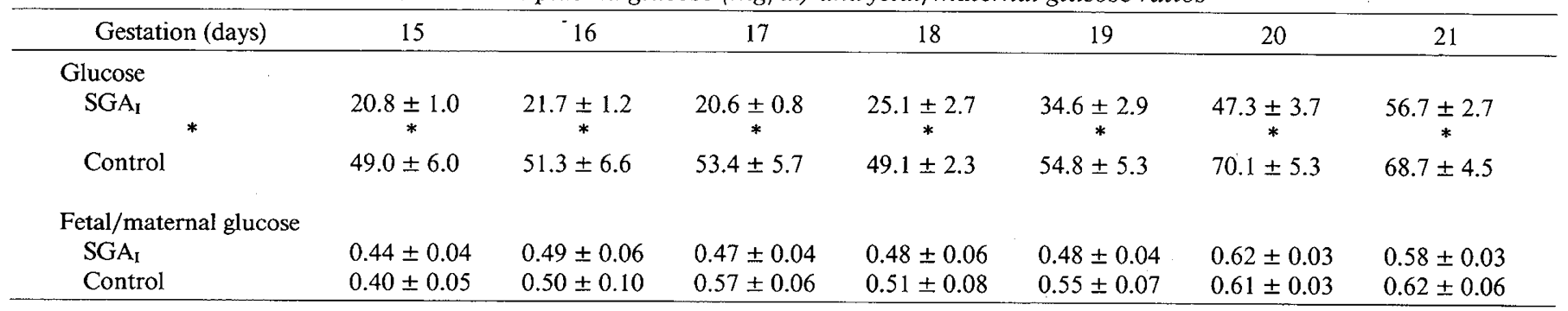

$* \mathrm{p}<.01$ to .001 .

diminished in $\mathrm{SGA}_{\mathrm{I}}$ fetuses compared to controls (day 17, 6.03 \pm 0.40 versus $9.03 \pm 0.50 \mathrm{mM}, p<0.01$ ). This resulted from the significant diminution of plasma amino acids in the hyperinsulinemic mothers (day 17, $2.51 \pm 0.39$ versus $3.88 \pm 0.39 \mathrm{mM}, p$ $<0.01$ ). While total values differed, no consistent differences in specific amino acids could be discerned. On days 20 and 21 , there were no differences between $\mathrm{SGA}_{1}$ and control fetuses nor between their mothers.

Plasma insulin concentrations were significantly diminished and glucagon concentrations increased (Fig. 3) in $\mathrm{SGA}_{\mathrm{I}}$ fetuses on days 17 through 21 . SGA and control fetuses had similar blood gas tensions and $\mathrm{pH}$ from days 18 to 21 . On day $19, \mathrm{SGA}_{\mathrm{I}}$ fetuses had values of pH 7.20 $\pm 0.008 ; \mathrm{PCO}_{2} 61 \pm 5$ torr; $\mathrm{PaO}_{2}$ $24 \pm 3$ torr; while controls had pH 7.20 $\pm 0.008 ; \mathrm{PCO}_{2} 60 \pm 5$ torr; $\mathrm{PO}_{2} 25 \pm 3$ torr. These values did not differ. The hypercarbia reflects the mild maternal hypoventilation resulting from anesthesia in both groups which we have previously observed.

Fetal weight correlated with fetal plasma glucose for $\mathrm{SGA}_{\mathrm{I}}$ and control fetuses on days 20 and 21 (day 20: $r=0.3256, n=55, p$ $<0.01$; day $21: r=0.5730, n=56, p<0.001)$, but not with fetal insulin concentrations.

Neonatal. Newborn $\mathrm{SGA}_{1}$ pups were significantly lighter than controls $(4.53 \pm 0.07$ versus $5.64 \pm 0.06 \mathrm{~g}, p<0.001)$ and had significantly diminished plasma glucose concentrations during the first $240 \mathrm{~min}$ of life (Fig. 4) and decreased plasma insulin concentrations at birth (Fig. 5). Plasma glucagon concentrations were significantly elevated at birth and $20 \mathrm{~min}$. (Fig. 5).

$S_{S A}$ pups had significantly diminished hepatic glycogen values from birth to $120 \mathrm{~min}$. Both $\mathrm{SGA}_{\mathrm{r}}$ and control pups decreased hepatic glycogen during the first $240 \mathrm{~min}$ (Table 2).

Hepatic PEPCK activity. Fetuses of hyperinsulinemic and control mothers had equally low hepatic cytosolic PEPCK activity which did not change during fetal life. Control pups significantly increased PEPCK activity between birth and $240 \mathrm{~min}$ while $\mathrm{SGA}_{\mathrm{I}}$ pups did not (Table 2).

\section{DISCUSSION}

Maternal hyperinsulinemia from day 14 until term reduces maternal and fetal plasma concentrations of glucose and amino acids and is associated with retarded fetal growth and delayed biochemical maturation. The effects of fuel limitation extend into the neonatal period since $\mathrm{SGA}_{\mathrm{I}}$ pups developed hypoglycemia because of limited hepatic glycogen stores and PEPCK activity. Fetal and neonatal glucagon secretion was appropriate under these circumstances but did not induce PEPCK or correct neonatal hypoglycemia.

The limitation of concentrations of maternal glucose from 
days 15 to 21 and amino acids from days 17 to 19 along with unaltered maternal/fetal ratios of these fuels indicates that maternal hyperinsulinemia reduced fetal fuel availability to different degrees. These were associated with limited fetal growth. The extent of limitation of glucose and amino acids could not be quantitated since we did not measure uteroplacental and umbilical blood flow; however, $\mathrm{SGA}_{\mathrm{I}}$ and control fetuses had similar arteriovenous blood gas tensions and $\mathrm{pH}$ suggesting that blood flow was normal in hyperinsulinemic mothers. Other factors such as acidosis and ketosis can also delay fetal growth. The normal plasma $\mathrm{BOHB}$ concentrations and $\mathrm{pH}$ in hyperinsulinemic mothers indicate that these did not contribute to growth retardation.

Insulin is a critical growth stimulating hormone during the perinatal period (10). Plasma insulin concentrations were significantly limited in $\mathrm{SGA}_{\mathrm{I}}$ fetuses by day 17 presumably as a result of diminished glucose and possibly amino acids. Because of limited sampling, we could not determine whether fetal insulin and glucagon secretion were altered before this time although glucose was limited earlier. These observations suggest that prolonged fetal hyperinsulinemia retarded fetal growth; however, numerous other factors as fuel availability were probably as important in causing growth retardation. For example, while fetal body weight correlated with fetal plasma glucose, it did not correlate with fetal plasma insulin.

Newborn $S_{\text {GA }}$ pups had significantly diminished plasma glu-

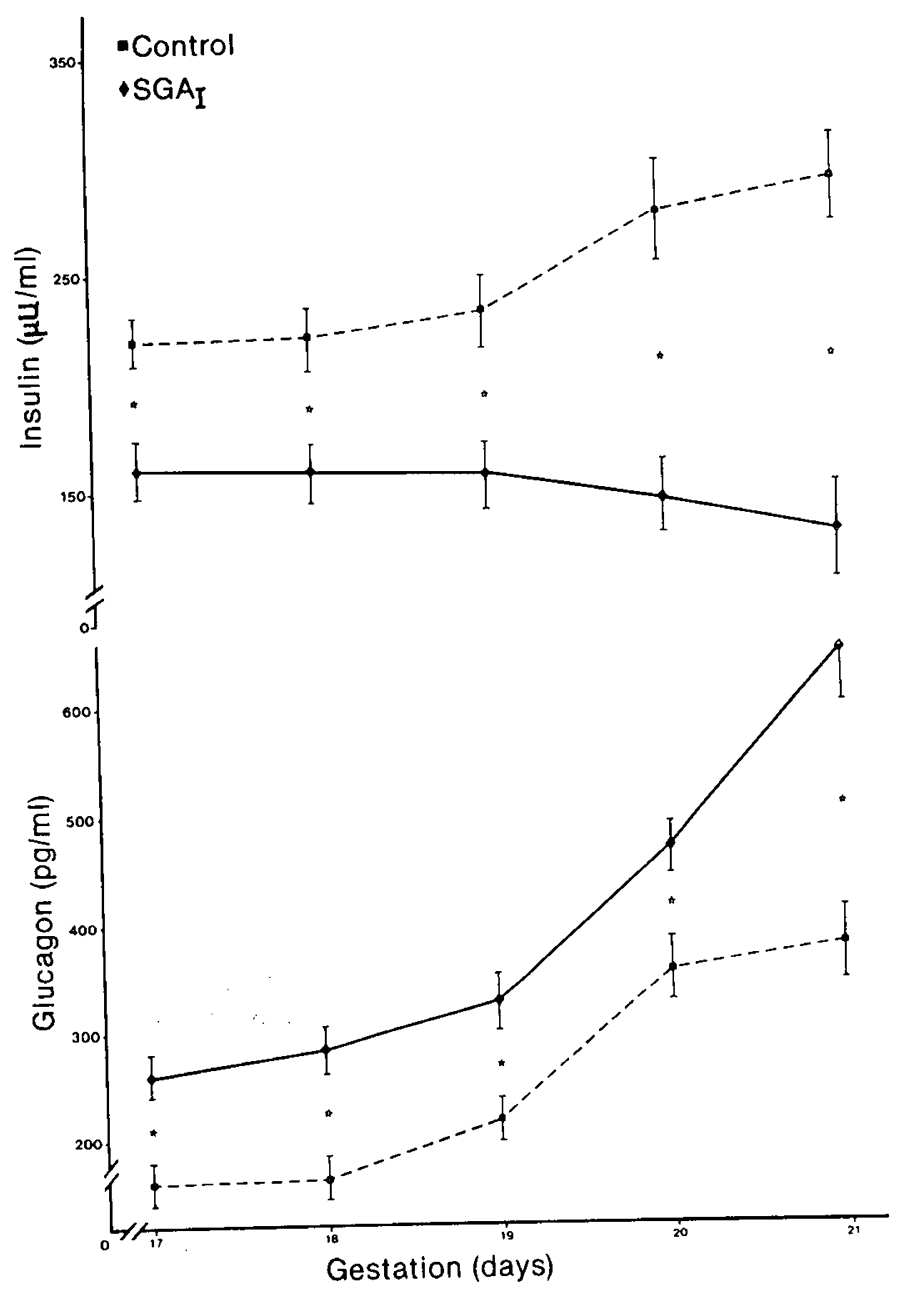

Fig. 3. Plasma concentrations of insulin and glucagon in pups of hyperinsulinemic $\left(\mathrm{SGA}_{1}\right)$ and control mothers. From day 17 until term, $S_{\mathrm{SG}}$ fetuses had significantly diminished insulin and elevated glucagon concentrations $\left({ }^{*} p<0.01\right.$ to 0.001$)$.

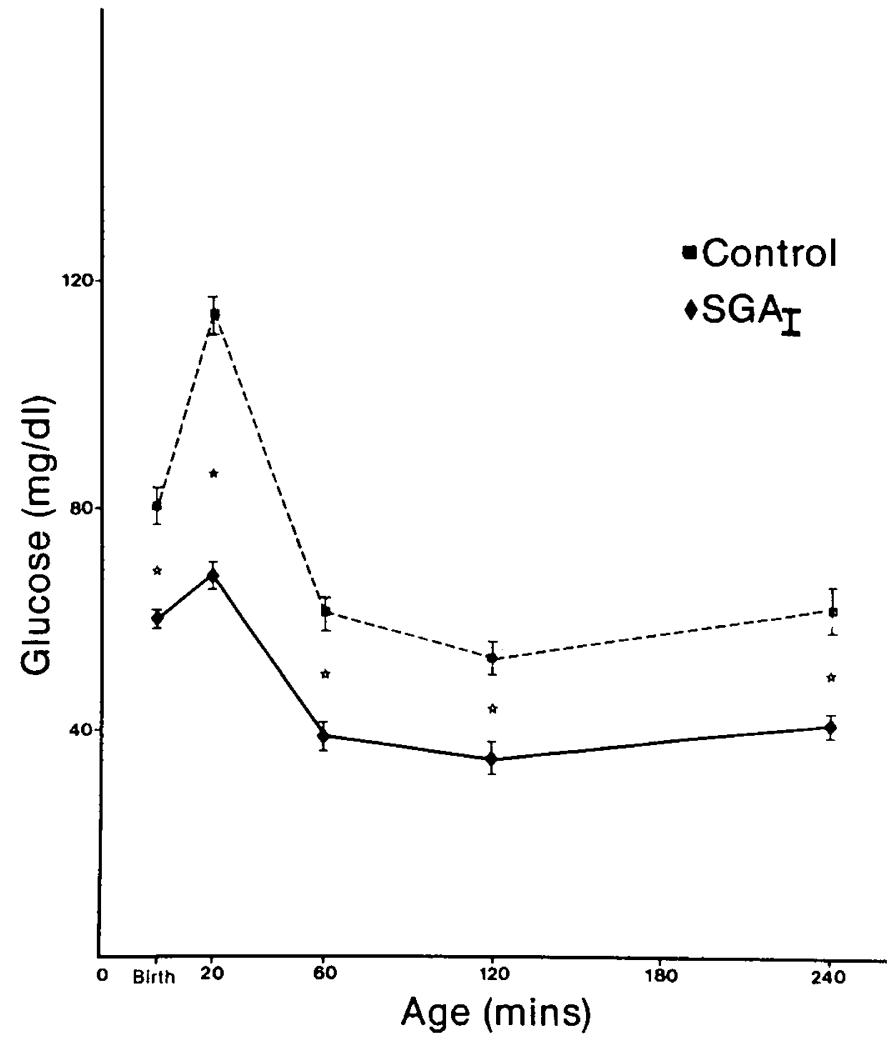

Fig. 4. Plasma glucose concentrations of newborn $\mathrm{SGA}_{1}$ and control pups. $\mathrm{SGA}_{\mathrm{I}}$ pups had significantly diminished values from birth to 240 $\min \left({ }^{*} p<0.01\right.$ to 0.001$)$.

hepatic glycogen stores and delayed induction of hepatic cytosolic PEPCK. The limited maternal glucose and amino acids resulted in diminished hepatic glycogen stores in the $\mathrm{SGA}_{1}$ pups.

Limited metabolic fuels during intrauterine life was associated with appropriately increased glucagon secretion in $\mathrm{SGA}_{1}$ fetuses. In addition, $\mathrm{SGA}_{\mathrm{I}}$ pups demonstrated a greater then expected cose concentrations from birth to $240 \mathrm{~min}$ as a result of limited neonatal glucagon surge compared to controls. These changes should not only have maintained plasma glucose concentrations but also facilitated hepatic PEPCK induction. Hepatic glycogen concentrations decreased in $\mathrm{SGA}_{\mathrm{I}}$ fetuses indicating an appropriate response to glucagon. On the other hand, the failure of the $\mathrm{SGA}_{\mathrm{I}}$ pups to increase hepatic PEPCK as control pups suggests a "resistance" to glucagon with respect to its role as a gluconeogenic enzyme precursor. Ninety percent of PEPCK activity is present in the cytosol $(11,12)$, and while the three other critical gluconeogenic enzymes appear during intrauterine life, PEPCK activity increases only after delivery $(13,14)$. During normal perinatal development, glucagon stimulates PEPCK induction by increasing intracellular cyclic $\operatorname{AMP}(15,16)$ while excessive insulin limits induction by inhibiting mRNA transcription (17, 18). We (3) and others $(13,19,20)$ have observed this relative "resistance" in rat pups rendered growth retarded by maternal uterine artery ligation.

Another cause of the neonatal hypoglycemia may be inappropriate modulation of insulin. While $S G A_{I}$ pups had significantly diminished insulin concentrations at birth, subsequent values did not differ from controls. Since $\mathrm{SGA}_{\mathrm{I}}$ pups were hypoglycemic compared to controls, their elevated insulin values relative to glucose suggest a possible inability to limit insulin secretion.

Our findings extend the initial observations of Grupposo et al. (5) who reported that term pups and day 20 fetuses of hyperinsulinemic mothers were significantly smaller and had lower plasma glucose and insulin concentrations than controls. In 

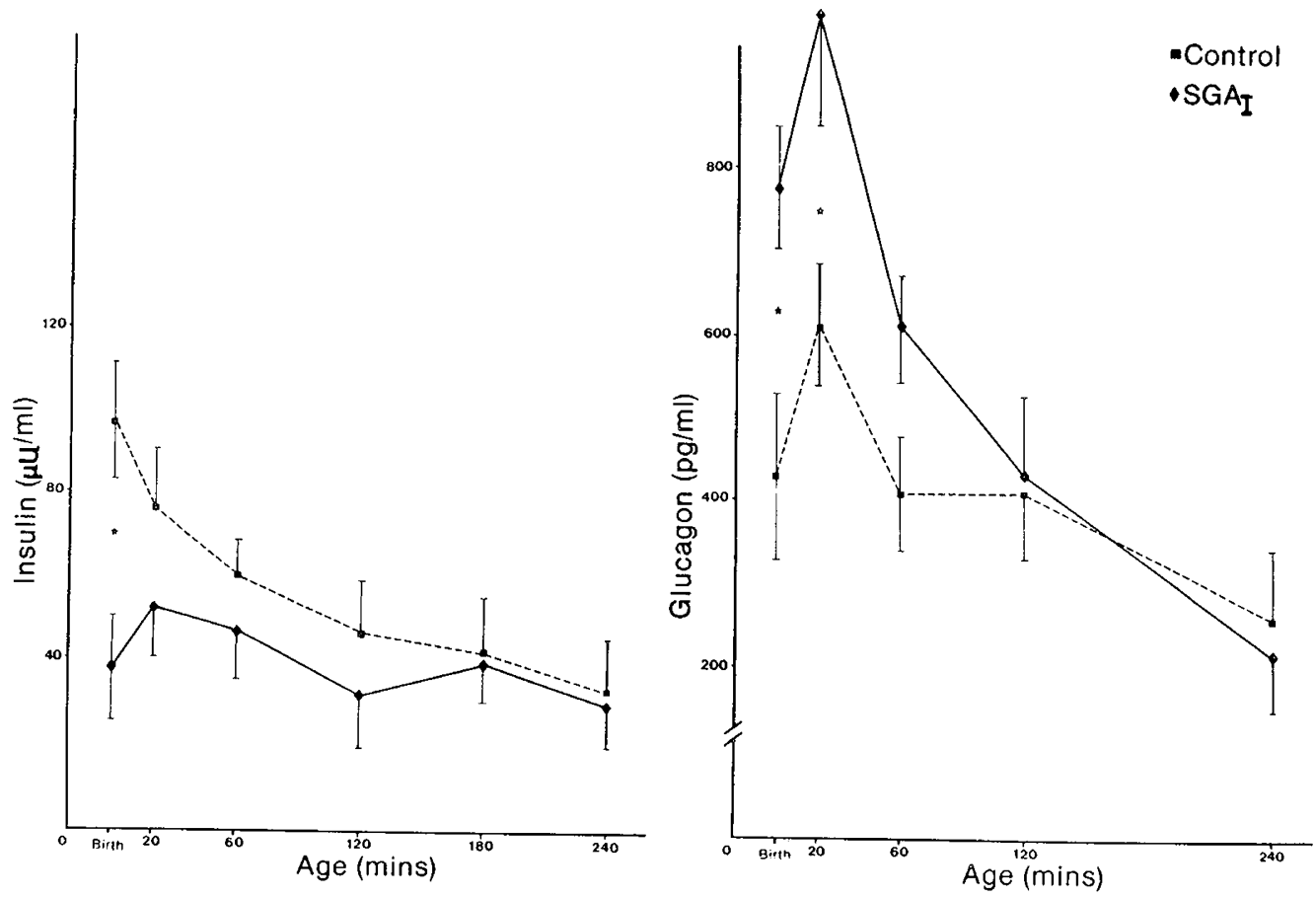

Fig. 5. Plasma insulin and glucagon concentrations of $\mathrm{SGA}_{1}$ and control pups. $\mathrm{SGA}_{1}$ pups had significantly diminished insulin concentrations at birth $\left({ }^{*} p<0.01\right)$ and significantly elevated glucagon concentrations at birth and 20 minutes $\left({ }^{*} p<0.01\right)$.

Table 2. Hepatic glycogen concentrations $(\mathrm{mg} / \mathrm{g}$ liver) and cytosolic PEPCK activity ( $\mu \mathrm{mol} / \mathrm{PEP} / \mathrm{g}$ liver/min)

\begin{tabular}{rccccc}
\hline Age (min) & 0 & 20 & 60 & \multicolumn{1}{c}{120} & 240 \\
\hline $\begin{array}{c}\text { Glycogen } \\
\text { SGA }\end{array}$ & $36.1 \pm 6.0$ & $20.1 \pm 2.1$ & $20.0 \pm 3.1$ & $17.0 \pm 5.4$ & $13.0 \pm 5.3$ \\
${ }^{*}$ & & $*$ & $*$ & $*$ \\
Control & $50.3 \pm 7.3$ & $43.2 \pm 6.4$ & $38.3 \pm 5.1$ & $23.4 \pm 4.1$ & $12.0 \pm 5.2$ \\
PEPCK & & & & \\
SGA & $0.092 \pm 0.014$ & & $0.134 \pm 0.012$ & $0.135 \pm 0.009$ \\
Control & $0.100 \pm 0.015$ & & & $0.127 \pm 0.013$ & $0.227 \pm 0.009$ \\
\hline$* 0.01$ to 001 & & & &
\end{tabular}

contrast to our observations, they reported a significantly diminished fetal/maternal glucose relationship on day 20 in hyperinsulinemic mothers suggesting impaired glucose transport. In addition, while we found significant limitations of maternal and fetal total amino acids associated with hyperinsulinemia from days 17 to 19 only, Grupposo et al. (5) reported diminished total maternal and fetal amino acid concentrations on day 21.5. These may represent differences in anesthesia or handling of the fetus.

While our model of maternal hyperinsulinemia resulted in sustained fetal hypoglycemia, the significant reductions in fetal total amino acids from days 17 to 19 were followed by normal values on days 20 and 21 . The mechanism for this is unclear. We can only speculate that the "antiinsulin factors" which normally develop during late gestation were sufficient in the hyperinsulinemic mother to correct plasma amino acid but not glucose concentrations.

In previous studies, we used maternal uterine artery ligation on day 18 in the rat as a model of "uteroplacental insufficiency." This retarded fetal growth (3) and was associated with limited fetal glucose and amino acids (4). While this was for a shorter period (days 18-21) than with maternal hyperinsulinemia, the offspring of mothers with uterine artery ligation were significantly smaller. The factor responsible for this difference was the alteration of gas exchange and $\mathrm{pH}$. Unlike $\mathrm{SGA}_{\mathrm{I}}$ fetuses, the fetuses of mothers with uterine artery ligation were hypercarbic, hypoxic, and acidotic for at least $48 \mathrm{~h}$ following ligation suggesting that maintenance of adequate blood gas tensions and $\mathrm{pH}$ may be an extremely important factor in determining fetal growth. This is consistent with models of chronic maternal hypoxia which profoundly retard fetal growth (21).

Recently a syndrome $(22,23)$ has been described of women who fail to develop the normally expected "diabetogenic state" (24) of late pregnancy. Such women have normal rather than attenuated glucose clearance during the third trimester and are at a 20 to $30 \%$ risk of bearing growth-retarded infants. It has been suggested that such women fail to develop one or all of the antiinsulin factors of late pregnancy and thereby limit fuel availability to the fetus. To the extent that maternal hyperinsulinemia limits fuel availability, this model in the rat mimics the "failed diabetogenic state" and may be useful for studies concerning this syndrome.

\section{REFERENCES}

1. Gruenwald P 1963 Chronic fetal distress and placental insufficiency. Biol Neonate 5:215

2. Ogata ES, Bussey ME, Finley S, LaBarbera A 1985 Altered growth, hypoglycemia, hypoalaninemia and ketonemia in the young rat: postnatal consequences of intrauterine growth retardation. Pediatr Res 19:32-27

3. Bussey M, Finley S, LaBarbera A, Ogata ES 1985 Hypoglycemia in the newborn growth-retarded rat. Delayed phosphoenolpyruvate carboxykinase induction despite increased glucagon availability. Pediatr Res 19:363-367

4. Ogata ES, Bussey ME, Finley S 1986 Altered gas exchange, limited glucose and branched chain amino acids, and hypoinsulinism retard fetal growth in the rat. Metabolism 35:970-977

5. Grupposo PA, Migliori R, Susa JB, Schwartz R 1981 Chronic maternal hyperinsulinemia and hypoglycemia. Biol Neonate 40:113-120 
6. Girard JR, Ferre P, Gilbert M, Kervran A, Assan R, Marlis EB 1977 Fetal metabolic response to maternal fasting in the rat. Am J Physiol 232:E456462

7. Snedecor GW, Cochran WG 1972 Statistical Methods. Iowa University Press, Ames, IA

8. Ogata ES, Metzger BE, Freinkel N 1981 Effect of the conceptus on glucose turnover during the fasting hypoglycemia of late pregnancy in the rat. Metabolism 30:487-492

9. Miettinin EL, Kliegman RL, Tserng KY 1983 Fetal and neonatal responses to extended maternal canine starvation. I. Circulating fuels and glucose and lactate turnover. Pediatr Res 17:634-638

10. Hill DJ, Milner RD 1985 Insulin as a growth factor. Pediatr Res 19:879-886

11. Shrago E, Lardy H, Nordlie RC, Foster DO 1963 Metabolic and hormonal control of phosphoenolpyruvate carboxykinase and malic enzyme in rat liver. J Biol Chem 238:3188-3192

12. Lardy HA, Foster DO, Shrago E, Ray PO 1964 Metabolic and hormonal regulation of phosphoenolpyruvate synthesis. Adv Enzyme Regul 2:39-47

13. Pollack A, Susa JB, Stonestreet BS, Schwartz R, Oh W 1979 Phosphoenolpyruvate carboxykinase in experimental intrauterine growth retardation in rats. Pediatr Res 13:175-177

14. Ballard FJ, Hanson RW 1967 Phosphoenolpyruvate carboxykinase and pyruvate carboxylase in developing rat liver. Biochem $\mathrm{J}$ 104:866-871

15. Girard JR, Caquet D, Bal D, Guillet I 1973 Control of rat liver phosphoenolpyruvate, glucose 6 phosphatase, and phosphoenolpyruvate carboxykinase activities by insulin and glucagon during the perinatal period. Enzyme $15: 272-285$
16. Yeung D, Oliver IT 1968 Induction of phosphoenolpyruvate carboxylase in neonatal and rat liver by adenosine $3^{\prime}, 5^{\prime}$-cyclic monophosphate. Biochemistry 7:3231-3239

17. Beale E, Andreone T, Koch S, Granner M, Granner D 1984 Insulin and glucagon regulate cytosolic phosphoenolpyruvate carboxykinase (GTP) mRNA in rat liver. Diabetes 33:328-332

18. Garcia-Ruiz JD, Ingram R, Hanson RQ 1978 Changes in hepatic messenger RNA for phosphoenolpyruvate carboxykinase (GTP) during development. Proc Natl Acad Sci USA 75:4189-4193

19. Vinicor F, Higdon G, Clark J 1976 Development of glucagon sensitivity in neonatal rat liver. J Clin Invest 58:571-578

20. Blazquez E, Rabalacava B, Montesano R 1976 Development of insulin and glucagon binding and the adenylate cyclase response in liver membranes of the prenatal, postnatal, and adult rat. Evidence of glucagon "resistance". Endocrinology 98:1014-1023

21. Van Geijn N, Kaylor W, Nicola K, Zuspan F 1980 Induction of severe intrauterine growth retardation in the Sprague-Dawley rat. Am J Obstet Gynecol 137:43-47

22. Khouzami V, Ginshang DS, Daikoku NH, Johnson JW 1981 The glucose tolerance test as a means of identifying intrauterine growth retardation. Am J Obstet Gynecol 139:423-430

23. Sokol RD, Kazzi GH, Kalhan S, Pillay S 1982 Identifying the pregnancy at risk for intrauterine growth retardation: possible usefulness of the intravenous glucose tolerance test. Am J Obstet Gynecol 143:220-223

24. Freinkel N 1980 Of pregnancy and progeny. Diabetes 29:1023-1035 